\title{
Clinical Characteristics of Foreign-Imported COVID-19 Cases in Xi'an, China
}

\author{
Li Zhang ${ }^{1,2, *}$ \\ Minjie Liu ${ }^{2,3, *}$ \\ Jianying $\mathrm{Li}^{2,4, *}$ \\ Xiaoli $\mathrm{Li}^{3, *}$ \\ Li Cheng ${ }^{3}$ \\ Yahong $\mathrm{ji}^{3}$ \\ $\mathrm{Na} \mathrm{Li}{ }^{3}$ \\ Junning Wang $\mathbb{I D}^{2,3}$
}

'Department of Intensive Care Unit, Honghui Hospital, Xi'an Jiaotong University, Xi'an, Shaanxi, 7I0054, People's Republic of China; ${ }^{2}$ Xi'an Public Health Center, Xi'an, Shaanxi, 710200, People's Republic of China; ${ }^{3}$ Department of Respiratory, Honghui Hospital, Xi'an Jiaotong University, Xi'an, Shaanxi, 710054, People's Republic of China; ${ }^{4}$ The Department of Respiratory Medicine, Xi'an Central Hospital, The Affiliated Hospital of Xi'an Jiaotong University College of Medicine, Xi'an, Shaanxi, 7I0003, People's Republic of China

*These authors contributed equally to this work
Background: Effective management of foreign-imported COVID-19 cases is a new and great challenge for China. Our study focused on the foreign-imported COVID-19 cases to provide detailed data for insights into the prevention, early diagnosis, treatment and control of imported COVID-19.

Methods: For this observational and retrospective study, we investigated the clinical characteristics of imported COVID-19 cases that were confirmed by real-time RT-PCR in the Xi'an Public Health Center from 29 March 2020 to 31 August 2020.

Results: Of the 79 patients with COVID-19, 19 (24.1\%) had exposure to confirmed COVID19 patients, 15 (19.0\%) had exposure to suspicious COVID-19 patients, and $45(56.9 \%)$ had an unclear history of exposure to confirmed patients. The mean age of the patients was 38 years, and $70(88.7 \%)$ patients were male. Except for 2 severe cases, the remaining 58 (73.4\%) cases displayed mild or moderate symptoms, and 19 (24.2\%) infected patients were asymptomatic. Twenty-one (26.6\%) patients were not diagnosed until a third or later nucleic acid test. Ten (12.7\%) patients had chronic diseases. The most common manifestations of the patients were cough [18 (22.8\%) cases], fever [9 (11.4\%) cases] and sore throat [9 $(11.4 \%)$ cases]. Forty-one (51.9\%) cases showed abnormal chest CT images, To date, all patients have been discharged, and no patient has died.

Conclusion: The imported COVID-19 cases in Xi'an were mainly young and middle-aged adults with mild or moderate symptoms who had a low rate of comorbidity, showed favourable laboratory and chest CT images, and had a better prognosis. Notably, for suspected COVID-19 cases, at least three consecutive nucleic acid tests should be carried out to avoid missed detection of infected patients. Except for severe cases, high-level medical resources are not necessary in most cases.

Keywords: COVID-19, SARS-CoV-2, clinical characteristics, foreign-imported cases, pneumonia

\section{Introduction}

In December 2019, a cluster of cases of unexplained pneumonia occurred in Wuhan, Hubei Province. ${ }^{1-3}$ A new type of coronavirus was isolated from airway epithelial cells of infected patients, which was named severe acute respiratory syndrome coronavirus 2 (SARS-CoV-2), and in February 2020, the World Health Organization (WHO) officially designated the disease coronavirus disease 2019 (COVID-19). ${ }^{4}$ The COVID-19 disease clinically manifests as asymptomatic infection or mild-to-severe pneumonia. ${ }^{5}$ Owing to the efficient prevention and control measures implemented by the government, the epidemic of COVID-19 in mainland China has been well controlled since March 2020. Few new domestic cases have
Correspondence: Junning Wang Department of Respiratory, Honghui Hospital, Xi'an Jiaotong University, No. 555, Youyi East Road, Nanshaomen, Xi'an, Shaanxi, 710054, People's Republic of China

Tel +8602962818354

Fax +8602962818354

Email wangjunningde@।63.com 
been reported since late March $2020 .^{6}$ As the situation in other countries started rapidly deteriorating, COVID-19 rapidly developed into a global pandemic, as declared by the WHO. ${ }^{7}$ Globally, as of 20 March 2021, there have been more than 121 million confirmed cases of COVID19, including 2.69 million deaths. ${ }^{8}$ Although a number of vaccine candidates are being developed, clinical trials are still ongoing, and the efficacy and safety of the vaccines are uncertain. The complexity and high volume of international air travel cause COVID-19 to spread rapidly., ${ }^{9,10}$ The government has taken many measures to curb the spread of overseas imported COVID-19, including detailed screening based on history of epidemiology, body temperature and clinical symptoms. Recent reports showed that asymptomatic patients could transmit COVID-19 via close contact with other people, ${ }^{11,12}$ which challenges this approach, as symptom-based screening may potentially miss travellers incubating the disease or travellers concealing symptoms during travel and contribute to foreign-imported COVID-19 cases. Currently, real-time reverse transcription polymerase chain reaction (RT-PCR) for the detection of SARS-CoV-2 RNA in respiratory samples is a reliable test for detecting both symptomatic and asymptomatic COVID-19. ${ }^{13,14}$

Accompanying the increase in the number of people travelling to China, imported COVID-19 cases have also significantly increased. To further control the spread of imported cases from abroad, 12 cities were designated on 23 March 2020 as first entry points for international flights to screen, isolate, diagnose and treat imported COVID-19 cases. Xi' an is one of the cities with imported cases. ${ }^{15}$ As of 20 March 2021, a total of 5195 patients from abroad were reported in China, and no patient death was reported. ${ }^{16}$ All incoming travellers are required to go through entry screening procedures and have oropharyngeal specimens or nasopharyngeal specimens collected for COVID-19 testing. If the passenger's point of entry is Xi'an, China, symptomatic individuals are sent to Xi'an Public Health Center for medical attention and additional COVID-19 testing. Individuals with no symptoms are sent to a hotel for quarantining for 14 days, and body temperature and health status are recorded every day. In hotel quarantine, individuals who develop symptoms such as coughing, runny nose or fever are sent to Xi'an Public Health Center for COVID-19 testing. When COVID-19 cases are confirmed, the patients are hospitalized in negative pressure isolation rooms. To date, limited studies on the epidemic and clinical characteristics of foreign imported COVID-19 in China have been conducted. Our study focused on the foreign imported COVID-19 cases at the Xi'an Public Health Center to analyse the clinical and laboratory characteristics in order to provide detailed data for valuable insights into the prevention, early diagnosis, treatment and control of imported COVID-19.

\section{Materials and Methods Study Design and Participants}

For this observational and retrospective study, clinical data records were collected from the Xi'an Public Health Center, which has been designated by the government to treat to foreign-imported patients with COVID-19 in Shaanxi Province. Epidemiological and clinical data of the confirmed cases of COVID-19 were obtained from 29 March 2020 to 31 August 2020. COVID-19 was diagnosed according to World Health Organization interim guidelines. ${ }^{17}$ Laboratory confirmation of COVID-19 was defined as a positive result for detection of SARS-CoV-2 by RT-PCR from nasal and pharyngeal swab samples or sputum specimens after admission by the Shaanxi Provincial Centre for Disease Control and Prevention (CDC).

\section{Data Collection}

The patient clinical data were retrieved from the electronic medical record system and attending doctors, and general information, including epidemiological, demographic, and clinical features and laboratory and chest computed tomography imaging (CT) characteristics as well as treatment details and patient outcome data were collected using a standardized case report form. The data were reviewed by two well-trained members of the study team. If information was not clear, the researcher contacted the doctor for clarification. Clinical features include fever, shortness of breath, headache and mental disorder symptoms, muscle ache, sore throat, rhinorrhoea, chest pain, diarrhoea, fatigue, and stuffy nose. Past comorbidities, including hypertension, coronary heart disease, respiratory system diseases, digestive system disease, nervous system diseases, malignant tumour, chronic kidney disease, diabetes, HIV infection and chronic liver disease, were collected. The following results from the first laboratory test after the patient was hospitalized (blood tests were usually taken within the first 24 hours of admission) were collected: routine blood tests (including white blood cell count, lymphocyte count, neutrophil count, monocyte count, platelet 
count, eosinophil count, and haemoglobin), C-reactive protein (CRP), erythrocyte sedimentation rate (ESR), SARS-CoV-2 nucleic acid, and IgG and IgM antibody response in COVID-19. All patients underwent chest CT examination at least once. During our study period, we recorded the first chest $\mathrm{CT}$ examination of all patients. The countries that the imported cases had visited within 14 days were defined as the source of their infection. The date of onset of the disease was defined as the date of the onset of symptoms. The Human Research Ethics Committee of Honghui Hospital, Xi'an Jiaotong University, approved the present study protocol (No. 202009002) before the study onset and complied with the principium plan in the Helsinki Declaration (as revised in 2013). Written informed consent was waived by the Ethics Commission because the study was a retrospective analysis. The information from the patients we studied was anonymized.

\section{Strategy for Nucleic Acid Tests}

During the COVID-19 outbreak, travellers who come to Xi'an, China, by plane undergo a COVID-19 nucleic acid test at the airport areas when they disembark, as do all travellers from where the disease is epidemic. Once a suspected case is admitted to Xi'an Public Health Center, nasal and pharyngeal swab samples were collected and sent to the Shaanxi CDC for confirmation via RT-PCR within 24 hours after admission. The RT-PCR assays targeting the open reading frame $1 \mathrm{ab}(\mathrm{ORF} 1 \mathrm{ab})$ and nucleocapsid (N) genes of SARS-CoV-2 used 2019-nCov nucleic acid detection reagent (Bio-germ, Shanghai, China), the thresholds were less than 40 , and positive results require both ORF1ab and $\mathrm{N}$ genes to be positive, or any target positive repeat test was still positive.

If the nucleic acid test is positive, the patient is diagnosed with COVID-19. If it is negative, the patient is tested for SARS CoV-2 by RT-PCR once a day for the next two days. After treatment, if there is no fever, no obvious respiratory symptoms or other symptoms and the patient's condition improves, the patient is discharged after passing two negative detection tests for SARS-CoV-2 by RT-PCR at least twice in intervals of 24 hours.

\section{Statistics}

If continuous measurements are normally distributed, they are expressed as the means \pm standard deviations (SDs). Additionally, if the distribution is not normal, they are expressed as medians with interquartile ranges $(25 \%$ and
75\%). Categorical variables are presented as absolute values with percentages (\%). We also evaluated whether the laboratory test results were outside the normal range, and these were expressed as increasing or decreasing. All statistical analyses were performed using SPSS software (standard version 19.0; SPSS Inc., Chicago, IL, USA).

\section{Results \\ Demographic, Baseline and Clinical Characteristics of Patients Infected with COVID-19}

In this study, 79 cases of COVID-19 infection in Xi'an Public Health Centre were investigated. All these cases were imported infections, and there were no domestic cases. The 79 foreign-imported cases were from 10 countries: 27 cases $(34.18 \%)$ from Singapore, 18 cases $(22.78 \%)$ from Russia, $13(11.46 \%)$ cases from Kazakhstan, and the remaining from Pakistan (7, 8.86\%), Azerbaijan (6, 7.59\%), Belgium (2, 2.53\%), the United Kingdom (2, 2.53\%), Spain (2, 2.53\%), Cambodia (1, $1.26 \%$ ), and Sweden (1, 1.26\%). Among them, 9 patients $(11.3 \%)$ were female, and 70 patients $(88.7 \%)$ were male. With a mean age of 38 years ( $38 \pm 10)$, young and middleaged people comprised a large proportion of cases; 14 patients $(17.7 \%)$ were aged $18-24$ years, 56 patients (70.8\%) were aged $25-49$ years, 9 patients $(11.3 \%)$ were aged 50-64 years, no patients $(0.0 \%)$ were under 18 years old, and no patients $(0.0 \%)$ were over 65 years old. The minimum age was 19 , and the maximum age was 57 . Nineteen (24.1\%) cases had exposure to confirmed COVID-19 patients, $15(19.0 \%)$ cases had exposure to suspicious COVID-19 patients, and 45 (56.9\%) cases did not have a clear history of exposure to a confirmed COVID-19 case. Thirteen (19 of 79, 16.5\%) patients had a history of infection with COVID-19. Of all 79 patients, 10 cases $(12.6 \%)$ had a history of chronic diseases, the most common of which was hypertension $(7.59 \%)$, followed by diabetes $(2.53 \%)$, respiratory system diseases (1.26\%), and chronic liver disease (1.26\%). In terms of clinical classification, 19 (24.2\%) patients had asymptomatic infection, $19(24.2 \%)$ patients were mild type, 39 (49.1\%) patients were moderate type, $2(2.5 \%)$ patients were severe type, and no patients were critically ill. The most common clinical symptoms were cough, fever and sore throat, which accounted for 18 cases (22.8\%), 9 cases (11.4\%) and 9 cases (11.4\%), respectively. In addition, 5 cases $(6.3 \%)$ had shortness of breath, 5 cases $(6.3 \%)$ had 
rhinorrhoea, 3 cases (3.8\%) had chest pain, 6 cases $(7.6 \%)$ had diarrhoea, 5 cases $(6.3 \%)$ had fatigue, 6 cases $(7.6 \%)$ had stuffy nose, 2 cases $(2.5 \%)$ had headache and mental disorder symptoms. The imported cases had developed symptoms before arrival (mean 6 days, range 1-30 days before arrival). Of the imported cases, 58 (73.4\%) cases were diagnosed within 3 days, and another 21 (26.6\%) were diagnosed 3 days later. However, all were diagnosed within 14 days. As of the final follow-up date, all patients had been discharged, and no patient had died by the end of the observation period. The demographic, baseline and clinical characteristics of the patients are shown in Table 1.

\section{Laboratory Findings for Patients Infected with COVID-19}

Upon admission, the median white blood cell (WBC) count was $6.54 \times 10^{9} / \mathrm{L}$ (IQR $6.49-7.61 \times 10^{9} / \mathrm{L}$ ); 2 patients (2.5\%) had lower WBC counts than the normal range (3.5 $\left.\times 10^{9} / \mathrm{L}\right)$, and 5 patients $(6.3 \%)$ had WBC counts greater than the normal range $\left(9.5 \times 10^{9} / \mathrm{L}\right)$. The median lymphocyte count was $2.06 \times 10^{9} / \mathrm{L}$ (IQR: $1.65-2.35 \times 10^{9} / \mathrm{L}$ ); 3 patients (3.8\%) had lymphocytopenia (the lymphocyte count was less than $1.1 \times 10^{9} / \mathrm{L}$ ), and 2 patients $(2.5 \%)$ had lymphocytosis (the lymphocyte count was more than $\left.3.2 \times 10^{9} / \mathrm{L}\right)$. The median platelet count was $237 \times 10^{9} / \mathrm{L}$ (IQR: $\left.205-278 \times 10^{9} / \mathrm{L}\right)$; 1 patient $(1.3 \%)$ had platelets lower than the normal range $\left(125 \times 10^{9} / \mathrm{L}\right)$, and 6 patients (7.6\%) had platelets higher than the normal range $\left(350 \times 10^{9} / \mathrm{L}\right)$. The median neutrophil count was $4.12 \times 10^{9} /$ L (IQR: $\left.2.92-4.65 \times 10^{9} / \mathrm{L}\right)$; 2 patients $(2.6 \%)$ had neutrophil counts lower than the normal range $\left(1.8 \times 10^{9} / \mathrm{L}\right)$, and 6 patients $(7.6 \%)$ had neutrophil counts greater than the normal range $\left(6.3 \times 10^{9} / \mathrm{L}\right)$. The median monocyte count was $0.52 \times 10^{9} / \mathrm{L} \quad\left(\mathrm{IQR}: 0.43-0.65 \times 10^{9} / \mathrm{L}\right) ; 1$ patient $(1.3 \%)$ had monocyte counts lower than the normal range $\left(0.1 \times 10^{9} / \mathrm{L}\right)$, and 27 patients $(34.2 \%)$ had monocyte counts greater than the normal range $\left(0.6 \times 10^{9} / \mathrm{L}\right)$. The median eosinophil count was $0.10 \times 10^{9} / \mathrm{L}$ (IQR: $0.07-0.16 \times 10^{9}$ / L); 2 patients $(2.6 \%)$ had eosinophil counts lower than the normal range $\left(0.02 \times 10^{9} / \mathrm{L}\right)$, and 3 patients $(3.8 \%)$ had eosinophil counts greater than the normal range $\left(0.52 \times 10^{9}\right.$ / L). The median haemoglobin level was $146 \mathrm{~g} / \mathrm{L}$ (IQR: 136-155 g/L); 12 patients (15.2\%) had haemoglobin levels lower than the normal range $(130 \mathrm{~g} / \mathrm{L})$, and 1 patient $(1.3 \%)$ had a haemoglobin level greater than the normal range $(175 \mathrm{~g} / \mathrm{L})$. The median value of C-reactive protein (CRP) was $9 \mathrm{mg} / \mathrm{L}$ (IQR $8-10 \mathrm{mg} / \mathrm{L}$ ), and the erythrocyte sedimentation rate (ESR) was $7 \mathrm{~mm} / \mathrm{h}$ (IQR $6-13 \mathrm{~mm} / \mathrm{h}$ ). There were 4 patients (5.1\%) with high CRP and 10 patients $(12.7 \%)$ with high ESR. The laboratory findings at admission are shown in Table 2.

\section{SARS-CoV-2 Nucleic Acid and Serum Anti-SARS-CoV-2 IgG and lgM Antibody Responses}

During the diagnostic procedure, we found that 25 patients (31.4\%) had a positive SARS-CoV-2 nucleic acid result in the first test, and 33 patients $(41.8 \%)$ had a positive result in the second test. Unexpectedly, another 21 patients (26.6\%) did not obtain a SARS-CoV-2 nucleic acidpositive result until a third or later test. The positivity rate of serum anti-SARS-CoV-2 S-specific IgM antibodies was $65.8 \%$ (52 of 79). The positivity rate of serum antiSARS-CoV-2 S-specific IgG antibodies was 70.1\% (56 of 79). The positivity rate of serum simultaneous anti-SARSCoV-2 S-specific IgG and IgM antibodies was 50.6\% (40 of 79). Serum anti-SARS-CoV-2 S-specific IgG or IgM antibodies were not detectable in 14 (17.7\%) cases. SARS$\mathrm{CoV}-2$ nucleic acid and serum anti-SARS-CoV-2 IgG and IgM antibody responses are shown in Table 3.

\section{Chest CT Features of Patients Infected with COVID-19}

Of the 79 patients, 41 (51.9\%) patients showed abnormal chest computed tomography (CT) images, comprising 24 cases (30.4\%) of bilateral pneumonia and 17 cases $(21.5 \%)$ of unilateral pneumonia. Among the patients, 6 patients (7.6\%) showed pure ground-glass opacity (GGO) shadowing (Figure 1A), 21 patients (26.6\%) showed GGO with reticular and/or interlobular septal thickening (Figure $1 \mathrm{~B})$, and 13 patients (16.5\%) showed GGO with consolidation (Figure 1C), but consolidation was rare, with only 1 patient (1.3\%) showing consolidation (Figure 1D). Additionally, no cases of pleural effusion or pneumothorax occurred. Thirty-eight (48.1\%) patients had normal CT imaging. The chest $\mathrm{CT}$ features of patients infected with COVID-19 are shown in Table 4 and Figure 1.

\section{Discussion}

The COVID-19 pandemic developed rapidly into a global emergency, and quick adaptation and pragmatic measures have been taken by the government to address this emergency. Symptom-based screening and testing for COVID19 for inbound passengers were made widely accessible. 
Table I Demographic, Baseline and Clinical Characteristics of Patients Infected with COVID-19

\begin{tabular}{|c|c|}
\hline Variables & Patients $(n=79)$ \\
\hline \multicolumn{2}{|l|}{ Age $(y)$} \\
\hline Mean (SD) & $38 \pm 10$ \\
\hline Range & $19-57$ \\
\hline$<18$ & $0(0.0 \%)$ \\
\hline $18-24$ & $14(17.7 \%)$ \\
\hline $25-49$ & $56(70.8 \%)$ \\
\hline $50-64$ & 9 (II.3\%) \\
\hline$\geq 65$ & $0(0.0 \%)$ \\
\hline \multicolumn{2}{|l|}{ Sex } \\
\hline Female & 9 (II.3\%) \\
\hline Male & 70 (88.7\%) \\
\hline \multicolumn{2}{|l|}{ From countries } \\
\hline Singapore & 27 (34.18\%) \\
\hline Russia & $18(22.78 \%)$ \\
\hline Kazakhstan & $13(11.46 \%)$ \\
\hline Pakistan & 7 (8.86\%) \\
\hline Azerbaijan & $6(7.59 \%)$ \\
\hline Belgium & $2(2.53 \%)$ \\
\hline United Kingdom & $2(2.53 \%)$ \\
\hline Spain & $2(2.53 \%)$ \\
\hline Cambodia & I (I.26\%) \\
\hline Sweden & I (1.26\%) \\
\hline \multicolumn{2}{|l|}{ Clinical classification } \\
\hline Asymptomatic infection & 19 (24.2\%) \\
\hline Mild type & 19 (24.2\%) \\
\hline Moderate type & 39 (49.1\%) \\
\hline Severe type & $2(2.5 \%)$ \\
\hline Critically ill type & $0(0.0 \%)$ \\
\hline \multicolumn{2}{|l|}{ Comorbidities } \\
\hline Hypertension & $6(7.59 \%)$ \\
\hline Diabetes & $2(2.53 \%)$ \\
\hline Respiratory system diseases & I (1.26\%) \\
\hline Chronic liver disease & I (1.26\%) \\
\hline Coronary heart disease & $0(0.00 \%)$ \\
\hline Digestive system disease & $0(0.00 \%)$ \\
\hline Malignant tumour & $0(0.00 \%)$ \\
\hline Nervous system diseases & $0(0.00 \%)$ \\
\hline Chronic kidney disease & $0(0.00 \%)$ \\
\hline HIV infection & $0(0.00 \%)$ \\
\hline \multicolumn{2}{|l|}{ Epidemiological history } \\
\hline Confirmed COVID-19 & $19(24.1 \%)$ \\
\hline Suspicious COVID-19 patients & $15(19.0 \%)$ \\
\hline Unknown & $45(56.9 \%)$ \\
\hline History of infection with COVID-19 & $13(16.5 \%)$ \\
\hline
\end{tabular}

(Continued)
Table I (Continued).

\begin{tabular}{|l|l|}
\hline Variables & Patients (n=79) \\
\hline Signs and symptoms at admission & \\
Cough & $18(22.8 \%)$ \\
Fever & $9(11.4 \%)$ \\
Sore throat & $9(11.4 \%)$ \\
Diarrhoea & $6(7.6 \%)$ \\
Stuffy nose & $6(7.6 \%)$ \\
Shortness of breath & $5(6.3 \%)$ \\
Rhinorrhoea & $5(6.3 \%)$ \\
Fatigue & $5(6.3 \%)$ \\
Chest pain & $3(3.8 \%)$ \\
Headache and mental disorder symptoms & $2(2.5 \%)$ \\
Muscle ache & $0(0.0 \%)$ \\
Anorexia & $0(0.0 \%)$ \\
Nausea and vomiting & $0(0.0 \%)$ \\
\hline Onset of symptom to hospital admission (days) & $6(1-30)$ \\
\hline Time from hospitalization to confirmation (days) & \\
$\leq 3$ & $58(73.4 \%)$ \\
$>3$ & $21(26.6 \%)$ \\
\hline Clinical outcome & \\
Discharged & $79(100.00 \%)$ \\
Died & $0(0.0 \%)$ \\
\hline
\end{tabular}

Furthermore, all travellers received 14-day quarantine of close contacts to prevent further viral transmission. These timely and rigorous public health measures are vital to stem the pandemic and have also been observed in other countries. ${ }^{10,18}$ Based on administrative screening for all passengers entering China, many cases were confirmed in the early stage of COVID-19. ${ }^{6,19}$ In this study, 79 cases infected with COVID-19 were all imported infections and came from 10 other countries, mainly Russia, Singapore and Kazakhstan. This highlights the speed and extent of the spread of the disease owing to population movements. Previous research results also support that the incoming international epidemic of SARS-CoV-2 originated from covert coronavirus infections. ${ }^{20}$

The proportion of male patients was $88.7 \%$ in our study, which is different from that of the patients in Wuhan, as reported by Chen et al (68\%) and Huang et al $(73 \%),{ }^{12,21}$ and different from that of imported patients in Jiangsu Province reported by $\mathrm{Wu}$ et al $(48.75 \%){ }^{22}$ The 
Table 2 Laboratory Findings of Imported Patients Infected with COVID-19

\begin{tabular}{|l|l|l|l|l|}
\hline Variables & \multirow{2}{*}{ Normal Range } & \multicolumn{3}{|c|}{ Patients (n=79) } \\
\cline { 3 - 5 } & & Median (IQR) & Increased No. (\%) & Decreased No. (\%) \\
\hline White blood cell count $\left(\times 10^{9} / \mathrm{L}\right)$ & $3.5-9.5$ & $6.54(6.49-7.6 I)$ & $5(6.3 \%)$ & $2(2.5 \%)$ \\
\hline Lymphocyte count $\left(\times 10^{9} / \mathrm{L}\right)$ & $1.1-3.2$ & $2.06(1.65-2.35)$ & $2(2.5 \%)$ & $3(3.8 \%)$ \\
\hline Platelet count $\left(\times 10^{9} / \mathrm{L}\right)$ & $125-350$ & $237(205-278)$ & $6(7.6 \%)$ & $I(1.3 \%)$ \\
\hline Neutrophil count $\left(\times 10^{9} / \mathrm{L}\right)$ & $1.8-6.3$ & $4.12(2.92-4.65)$ & $6(7.6 \%)$ & $2(2.5 \%)$ \\
\hline Monocyte count $\left(\times 10^{9} / \mathrm{L}\right)$ & $0.1-0.6$ & $0.52(0.43-0.65)$ & $27(34.2 \%)$ & $1(1.3 \%)$ \\
\hline Eosinophil count $\left(\times 10^{9} / \mathrm{L}\right)$ & $0.02-0.52$ & $0.10(0.07-0.16)$ & $3(3.8 \%)$ & $2(2.5 \%)$ \\
\hline Haemoglobin $(\mathrm{g} / \mathrm{L})$ & $130-175$ & $146(136-155)$ & $1(1.3 \%)$ & $12(15.2 \%)$ \\
\hline CRP* $\geq 5.0(\mathrm{mg} / \mathrm{L})$ & $0.0-10.0$ & $9(8-10)$ & $4(5.1 \%)$ & $0(0.0 \%)$ \\
\hline ESR* $(\mathrm{mm} / \mathrm{h})$ & $0.0-15.0$ & $7(6-13)$ & $10(I 2.7 \%)$ & $0(0.0 \%)$ \\
\hline
\end{tabular}

Abbreviations: *CRP, C-reactive protein; *ESR, erythrocyte sedimentation rate.

mean age of patients was 38 years old in our study, which is significantly younger than that of patients in local cases reported in the previous study ${ }^{12,21}$ but close to that of imported patients reported by $\mathrm{Wu}$ et al and Liu et $\mathrm{al}^{6,22}$. The results might be related to the patients' occupational characteristics, eg, mainly young and middle-aged men working abroad or participating in international trade and international exchanges, while they settled in China and always returned home on holidays.

The most common clinical symptoms of COVID-19 were fever, dry cough, nasal congestion, fatigue, sore throat, diarrhoea and myalgia. ${ }^{5}$ As Wang et $\mathrm{al}^{23}$. reported, 98.6\% (136/138 cases) of COVID-19 patients had fever, and $26.1 \%$ (36/138 cases) were admitted to ICU wards

Table 3 SARS-CoV-2 Nucleic Acid and Serum Anti-SARS-CoV-2 $\lg$ and IgM Antibody Responses

\begin{tabular}{|l|l|}
\hline Variables & Patients (n=79) \\
\hline Number of nucleic acid tests & \\
I & $25(31.4 \%)$ \\
2 & $33(41.8 \%)$ \\
$\geq 3$ & $21(26.6 \%)$ \\
\hline COVID-I9-specific antibody & \\
$\operatorname{IgM}(+)$ & $52(65.8 \%)$ \\
$\operatorname{lgG}(+)$ & $56(70.1 \%)$ \\
$\operatorname{IgM}(+)$ and $\operatorname{lgG}(+)$ & $40(50.6 \%)$ \\
$\operatorname{IgM}(-)$ and $\operatorname{lgG}(-)$ & $14(17.7 \%)$ \\
\hline
\end{tabular}

because of serious complications. In our study, most imported cases had mild or moderate symptoms. The most common symptoms were cough and sore throat, which accounted for 18 cases (22.8\%) and 9 cases (11.4\%), respectively. Other clinical symptoms were rare. Only 2 cases had severe pneumonia. Approximately 11.4\% of the patients had fever, which was lower than the percentage reported in Wuhan. ${ }^{21,24}$ Nineteen $(24.2 \%)$ cases were asymptomatic infected. Therefore, airport screening via body temperature and clinical symptoms can help detect $75.8 \%$ of the imported COVID-19 patients. It is an effective measure to screen symptomatic imported patients when they arrive at airports. The symptoms of the confirmed cases in this study were less severe than those of patients in Wuhan. ${ }^{12,21,25}$ This finding is consistent with the results for the patients hospitalized in Zhejiang Province, ${ }^{26}$ mainly because of the isolation measures and routine detection of nucleic acids in the early stage, they all obtained timely diagnosis and treatment. Liang et $\mathrm{al}^{27}$. retrospectively analysed the confirmed COVID-19 cases in 31 provinces of China and found that the patients in the Hubei area were older than those in other parts of China, with a higher symptomatic burden, more comorbidities, and abnormal radiologic manifestations. The long waiting time from symptom onset to admission, serious illness and delayed hospitalization are independent risk factors increasing a poor prognosis. Because overseas personnel have early intervention, even 
A

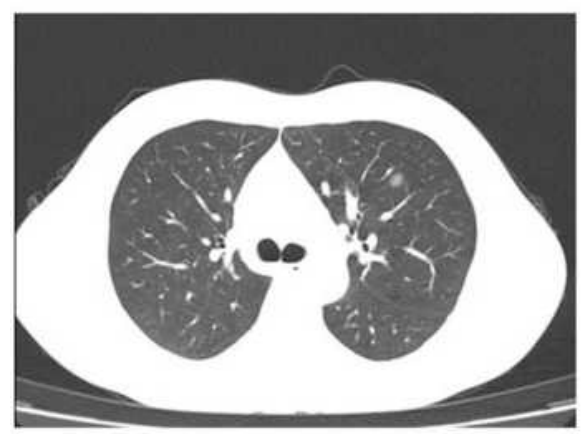

C

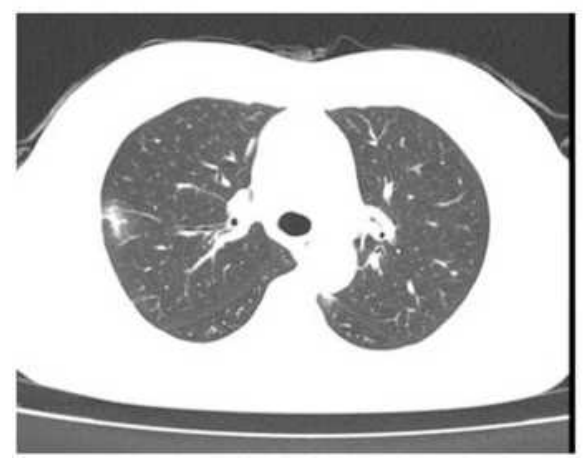

B

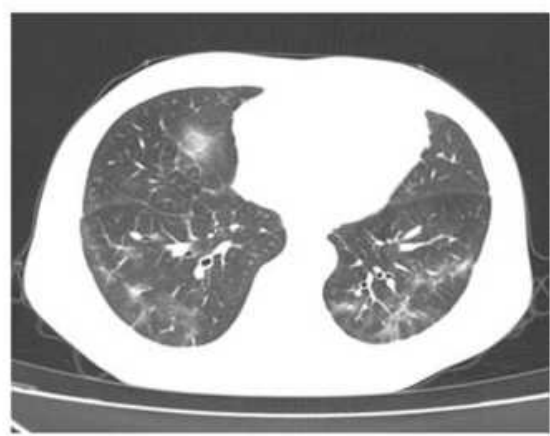

D

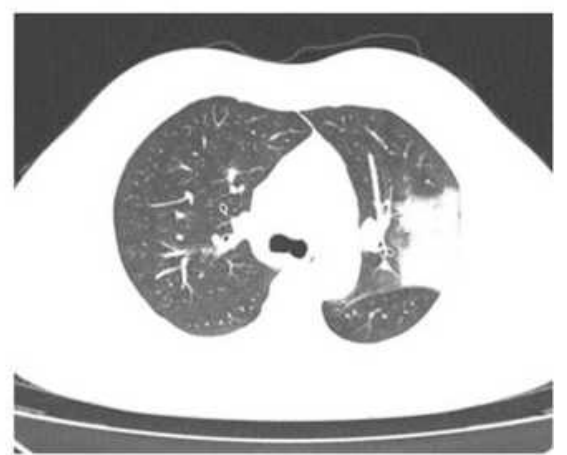

Figure I Chest CT images findings for four patients. (A) Chest computed tomography (CT) images of a 42-year-old male patient with COVID-I9 taken on August 9, 2020, showing left lung pure GGO. (B) Chest CT images of a 54-year-old male patient with COVID-19 taken on August 9, 2020, showing GGO with reticular and interlobular septal thickening in both lungs. (C) Chest CT images of a 40-year-old female patient with COVID-19 taken on April 2I, 2020, showing unilateral GGO with consolidation. (D) Chest CT images of a 33-year-old male patient with COVID-19 taken on April 27, 2020, showing left lung consolidation.

asymptomatic people achieve nucleic acid detection when entering the country. Therefore, these patients had milder symptoms and a good prognosis.

Some imported patients displayed long-term symptoms before arrival, the longest was 30 days in our study, and the patient still received positive nucleic acid test results for COVID-19. A long transmissibility period, prolonged

Table 4 Chest CT Findings of Patients with COVID-19

\begin{tabular}{|l|l|}
\hline CT Finding & Patients (n=79) (\%) \\
\hline No abnormal density shadow & $38(48.1 \%)$ \\
\hline $\begin{array}{l}\text { Location of lesion } \\
\text { Unilateral pneumonia } \\
\text { Bilateral pneumonia }\end{array}$ & $17(21.5 \%)$ \\
\hline $\begin{array}{l}\text { Type of lesion } \\
\text { Pure GGO* }\end{array}$ & $24(30.4 \%)$ \\
$\begin{array}{l}\text { GGO with reticular and/or interlobular } \\
\text { septal thickening }\end{array}$ & $6(7.6 \%)$ \\
GGO with consolidation & $21(26.6 \%)$ \\
Consolidation & $13(16.5 \%)$ \\
\hline
\end{tabular}

Abbreviation: *GGO, ground-glass opacity. viral shedding, ${ }^{28}$ and the reality that asymptomatic or paucisymptomatic patients can spread COVID-19 make disease control a challenge. ${ }^{29}$ Several studies have confirmed the existence of positive retests for nucleic acids in recovered COVID-19 patients. ${ }^{30-32}$ An et al ${ }^{31}$. showed that $38(14.50 \%)$ of 262 discharged patients tested positive for COVID-19 RNA, and Zhou et $\mathrm{al}^{33}$. showed that 17 $(17.35 \%)$ of 98 convalescent patients tested positive. These patients always displayed mild or moderate symptoms. ${ }^{31,33}$ Similarly, in our study, 13 (16.5\%) discharged patients retested positive for nucleic acid, and they presented no obvious clinical symptoms. The mechanisms underlying positive retests for nucleic acids are still undefined. Some experts proposed reasons possibly relating to sampling methodological, virological and immunological factors. ${ }^{34}$ Therefore, it is important to screen imported people who have a history of infection with COVID-19 even after treatment and discharge.

In terms of laboratory tests, earlier studies have shown that the leukocyte and lymphocyte counts are lower and the occurrence of lymphopoenia is higher in severe cases of COVID-19 infection. ${ }^{23,35}$ We also observed decreases 
in leukocyte and lymphocyte levels in the 2 severe cases, which is consistent with the conclusions of recent studies indicating that the virus invaded the body through the respiratory mucosa, stimulating a string of immune responses and causing severe inflammation and a cytokine storm in the body. ${ }^{36}$ Furthermore, the levels of CRP and ESR increased in COVID-19 cases and were even higher in severe cases, just as Wang et $\mathrm{al}^{37}$. showed that CRP levels were positively correlated with the severity of the disease. However, in this study, 72 patients had normal white blood cell counts, and only 3 patients had insufficient lymphocyte counts. Most patients had CRP (94.9\%) and ESR (87.3\%) within the normal ranges. The possible reasons for this result were the widespread testing of COVID-19 allowing early diagnosis and timely hospitalization.

In our research, all patients were diagnosed by nucleic acid testing. The first airport screening of specimens (throat swabs and sputum) tested for COVID-19 would be able to detect $31.4 \%$ of the imported COVID-19 patients, including those with symptomatic and asymptomatic COVID-19. We found that 21 patients $(26.6 \%)$ obtained positive results in three or more nucleic acid tests. COVID-19 was confirmed by viral nucleic acid detection with high specificity and a low sensitivity of $30-50 \%{ }^{38}$ It is common that symptoms and radiological findings support the diagnosis of COVID-19 in clinical work, while multiple consecutive nucleic acid tests with specimens (throat swabs or sputum) are negative, ${ }^{39}$ which highlights the necessity of follow-up and monitoring of travellers. Therefore, for suspected COVID-19 cases, we propose that at least three consecutive respiratory pathogenic nucleic acid tests be carried out to avoid missing diagnoses. Likewise, $73.4 \%$ (58 of 79) of imported patients were confirmed within 3 days after entry to the hospital due to the measures adopted by quarantine stations.

With further investigations of COVID-19, coronavirusspecific serum antibodies (IgM and $\operatorname{IgG}$ ) were added as the diagnostic standard. In our study, $63 \%$ of patients were IgM positive (52 of 79 patients), $70.1 \%$ were IgG positive (56 of 79 patients), and $50.6 \%$ were positive for $\mathrm{IgG}$ and IgM (40 of 79 patients). This is consistent with previous research results. ${ }^{40}$ However, our study revealed that there were 14 patients $(17.7 \%)$ with negative results, as another study showed that the timing of IgM and IgG antibody occurrence may be associated with various factors, such as age and complications. ${ }^{41}$ Therefore, this method needs to be combined with other detection methods to ensure complete evaluation.

Chest CT imaging is an important method for the diagnosis of COVID-19. CT changes at the early stage of COVID-19 mainly manifested as GGO and interstitial changes, especially in the peripheral part of the lung. However, as the disease progresses, pulmonary consolidation and pleural effusion can occur. In the case report from Wuhan, ${ }^{12}$ all patients had abnormal chest CT images detected on admission, and 98\% had bilateral involvement. In our study, the abnormal rate was lower, 41 cases $(51.9 \%)$ had abnormal images, 17 cases $(21.5 \%)$ showed unilateral pneumonia, and 24 cases (30.4\%) showed bilateral pneumonia. A national study showed that 157 of 877 patients with nonsevere disease (17.9\%) had negative CT imaging results. ${ }^{18}$ In our research, 38 patients $(48.1 \%)$ had no abnormal density shadows. Therefore, for patients with mild symptoms, chest CT imaging was not highly sensitive, it is necessary to combine clinical manifestations, laboratory investigations and chest imaging to screen patients.

In our study, the patients mainly received traditional Chinese medicine $(35.5 \%)$, antiviral treatment $(31.6 \%)$, antibiotic treatment $(7.6 \%)$ and glucocorticoid therapy $(2.5 \%)$. At present, all patients have been discharged from the hospital. To date, there is no specific medicine for the treatment of COVID-19 patients except for optimal supportive care. Vaccines are urgently needed to control the epidemic of COVID-19. Currently, a number of vaccines are being developed, several of which have accomplished latestage clinical trials and reported effective results. ${ }^{42}$ As of 20 March 2021, a total of 392.6 million vaccine doses have been administered. ${ }^{8}$ Because of the existence of virus mutations and other unpredictable factors, the efficacy and safety of vaccines are still uncertain and need to be further studied.

\section{Limitations}

Our study has some limitations. First, this was a retrospective study from a single centre in Xi'an, and a larger number of cases from other cities or provinces need to be recruited to make the study results more accurate. Second, our study focused on epidemiological and clinical aspects, only analysed the data at the time the patients were diagnosed, and did not perform dynamic examination to observe the processes and influencing factors of the disease. Third, there were only two severe cases in our study, and the differences in laboratory parameters between non-severe and severe cases were 
only descriptive. A larger sample of severe cases is necessary to verify our observation.

\section{Conclusion}

In summary, symptom-based screening and testing for COVID-19 for inbound passengers undoubtedly played an important role in controlling the spread of COVID-19. Our study showed that the imported COVID-19 cases in Xi'an were mainly young and middle-aged adults with mild or moderate symptoms who had a low rate of comorbidity, showed favourable laboratory and chest CT images, and had a better prognosis. Notably, for suspected COVID-19 cases, at least three consecutive nucleic acid tests should be carried out to avoid missed diagnoses of infected patients. Except in severe cases, high-level healthcare measures are not necessary.

\section{Author Contributions}

All authors made substantial contributions to conception and design, acquisition of data, or analysis and interpretation of data; took part in drafting the article or revising it critically for important intellectual content; agreed to submit to the current journal; gave final approval of the version to be published; and agree to be accountable for all aspects of the work.

\section{Disclosure}

The authors declare that they have no conflicts of interest for this work.

\section{References}

1. Du Z, Wang L, Cauchemez S, et al. Risk for transportation of coronavirus disease from wuhan to other cities in China. Emerg Infect Dis. 2020;26(5):1049-1052. doi:10.3201/eid2605.200146

2. Lu R, Zhao X, Li J, et al. Genomic characterisation and epidemiology of 2019 novel coronavirus: implications for virus origins and receptor binding. Lancet. 2020;395(10224):565-574. doi:10.1016/s01406736(20)30251-8

3. Chen L, Liu W, Zhang Q, et al. RNA based mNGS approach identifies a novel human coronavirus from two individual pneumonia cases in 2019 Wuhan outbreak. Emerg Microbes Infect. 2020;9(1):313-319. doi:10.1080/22221751.2020.1725399

4. Zhu N, Zhang D, Wang W, et al. A novel coronavirus from patients with Pneumonia in China, 2019. N Engl J Med. 2020;382(8):727-733. doi:10.1056/NEJMoa2001017

5. Jiang F, Deng L, Zhang L, et al. Review of the clinical characteristics of coronavirus disease 2019 (COVID-19). J Gen Intern Med. 2020;35 (5):1545-1549. doi:10.1007/s11606-020-05762-w

6. Liu XH, Lu SH, Chen J, et al. Clinical characteristics of foreign-imported COVID-19 cases in Shanghai, China. Emerg Microbes Infect. 2020;9 (1):1230-1232. doi:10.1080/22221751.2020.1766383

7. World Health Organization. Coronavirus Disease (COVID-19) Pandemic. Available from: https://www.who.int/emergencies/diseases/ novel-coronavirus-2019. Accessed April 4, 2020.
8. World Health Organization. WHO Coronavirus (COVID-19) Dashboard. Available from: https://covid19.who.int/. Accessed March 21, 2021.

9. Wilson ME, Chen LH. Travellers give wings to novel coronavirus (2019-nCoV). J Travel Med. 2020;27(2):1-3. doi:10.1093/jtm/taaa015

10. Wells CR, Sah P, Moghadas SM, et al. Impact of international travel and border control measures on the global spread of the novel 2019 coronavirus outbreak. Proc Natl Acad Sci U S A. 2020;117 (13):7504-7509. doi:10.1073/pnas.2002616117

11. Yang NL F, Wu JY. [Pulmonary rehabilitation guidelines in the principle of $4 \mathrm{~S}$ for patients infected with 2019 novel coronavirus (2019-nCoV)]. Zhonghua Jie He He Hu Xi Za Zhi. 2020;43:E004. doi:10.3760/cma.j.issn.1001-0939.2020.0004

12. Huang C, Wang Y, Li X, et al. Clinical features of patients infected with 2019 novel coronavirus in Wuhan, China. Lancet. 2020;395 (10223):497-506. doi:10.1016/s0140-6736(20)30183-5

13. Hoehl S, Rabenau H, Berger A, et al. Evidence of SARS-CoV-2 infection in returning travelers from Wuhan, China. $N$ Engl $J$ Med. 2020;382(13):1278-1280. doi:10.1056/NEJMc2001899

14. Rothe C, Schunk M, Sothmann P, et al. Transmission of 2019-nCoV infection from an asymptomatic contact in Germany. $N$ Engl J Med. 2020;382(10):970-971. doi:10.1056/NEJMc2001468

15. Civil Aviation Administration of China, the Ministry of Foreign Affairs of the People's Republic of China, National Health Commission of the people's Republic of China, etal., Notice of the Civil Aviation Administration of China, the Ministry of Foreign Affairs of the People's Republic of China, National Health Commission of the people's Republic of China. the General Administration of Customs of the People's Republic of China and the State Immigration Administration on the entry of international flights destined for Beijing from the designated first entry point (No.2). Available from: http://www.caac.gov.cn/XXGK/XXGK/ TZTG/202003/t20200322_201625.html. Accessed March 22, 2020.

16. National health commission of the People's Republic of China, COVID-19 cases in China update on 24: 0020 March, 2021. Available from: http://www.nhc.gov.cn/xcs/yqfkdt/202103/2494ea0ce b9a49a09674f4d0ebf5e27a.shtml. Accessed March 21, 2021.

17. World Health Organization. Clinical management of severe acute respiratory infection when novel coronavirus $(\mathrm{nCoV})$ infections suspected: interim guidance; 2020. Available from: http://www.nhc.gov.cn/xcs/ yqfkdt/202103/2494ea0ceb9a49a09674f4d0ebf5e27a.shtml. Accessed March 20, 2020.

18. Reintjes R. Lessons in contact tracing from Germany. $B M J$. 2020;369:m2522. doi:10.1136/bmj.m2522

19. Guan W-J, Ni Z-Y, Hu Y, et al. Clinical characteristics of coronavirus disease 2019 in China. New Engl J Med. 2020;382(18):1708-1720. doi:10.1056/NEJMoa2002032

20. Qiu J. Covert coronavirus infections could be seeding new outbreaks. [published online ahead of print, 2020 Mar 20]. Nature. doi:10.1038/ d41586-020-00822-x

21. Chen N, Zhou M, Dong X, et al. Epidemiological and clinical characteristics of 99 cases of 2019 novel coronavirus pneumonia in Wuhan, China: a descriptive study. Lancet. 2020;395 (10223):507-513. doi:10.1016/s0140-6736(20)30211-7

22. Wu J, Liu J, Zhao X, et al. Clinical characteristics of imported cases of coronavirus disease 2019 (COVID-19) in Jiangsu Province: a Multicenter Descriptive Study. Clin Infect Dis. 2020;71 (15):706-712. doi:10.1093/cid/ciaa199

23. Wang D, Hu B, Hu C, et al. Clinical characteristics of 138 hospitalized patients with 2019 novel coronavirus-infected pneumonia in Wuhan, China. JAMA. 2020;323(11):1061-1069. doi:10.1001/ jama.2020.1585

24. Huang L, Zhang $\mathrm{X}, \mathrm{Xu} \mathrm{A}$. Effectiveness of interventions as part of the One Health approach to control coronavirus disease 2019 and stratified case features in Anhui Province, China: a real-world population-based cohort study. One Health. 2021;12:100224. doi:10.1016/j.onehlt.2021.100224 
25. Wei Y, Lu Y, Xia L, et al. Analysis of 2019 novel coronavirus infection and clinical characteristics of outpatients: an epidemiological study from a fever clinic in Wuhan, China. J Med Virol. 2020;92 (11):2758-2767. doi:10.1002/jmv.26175

26. $\mathrm{Xu} X-\mathrm{W}, \mathrm{Wu}-\mathrm{X}-\mathrm{X}$, Jiang $\mathrm{X}-\mathrm{G}$, et al. Clinical findings in a group of patients infected with the 2019 novel coronavirus (SARS-Cov-2) outside of Wuhan, China: retrospective case series. BMJ. 2020: m606. doi:10.1136/bmj.m606.

27. Liang W-H, Guan W-J, Li C-C, et al. Clinical characteristics and outcomes of hospitalised patients with COVID-19 treated in Hubei (epicentre) and outside Hubei (non-epicentre): a nationwide analysis of China. Eur Respir J. 2020;55(6):2000562. doi:10.1183/ 13993003.00562-2020

28. Lan L, Xu D, Ye G, et al. Positive RT-PCR test results in patients recovered from COVID-19. JAMA. 2020;323(15):1502-1503. doi:10.1001/jama.2020.2783

29. Ling $Y, X u$ SB, Lin YX, et al. Persistence and clearance of viral RNA in 2019 novel coronavirus disease rehabilitation patients. Chin Med J. 2020;133(9):1039-1043. doi:10.1097/cm9.0000000000000774

30. Qu YM, Kang EM, Cong HY. Positive result of Sars-Cov-2 in sputum from a cured patient with COVID-19. Travel Med Infect Dis. 2020;34:101619. doi:10.1016/j.tmaid.2020.101619

31. An J, Liao X, Xiao T, et al. Clinical characteristics of recovered COVID-19 patients with re-detectable positive RNA test. Ann Transl Med. 2020;8(17):1084. doi:10.21037/atm-20-5602

32. Zhu H, Fu L, Jin Y, et al. Clinical features of COVID-19 convalescent patients with re-positive nucleic acid detection. J Clin Lab Anal. 2020;34(7):e23392. doi:10.1002/jcla.23392

33. Zhou F, Yu T, Du R, et al. Clinical course and risk factors for mortality of adult inpatients with COVID-19 in Wuhan, China: a retrospective cohort study. Lancet. 2020;395(10229):1054-1062. doi:10.1016/s0140-6736(20)30566-3
34. Hu Z, Song C, Xu C, et al. Clinical characteristics of 24 asymptomatic infections with COVID-19 screened among close contacts in Nanjing, China. Sci China Life Sci. 2020;63(5):706-711. doi:10.1007/s11427-020-1661-4

35. Du Y, Tu L, Zhu P, et al. Clinical features of 85 fatal cases of COVID-19 from Wuhan. A Retrospective Observational Study. Am J Respir Crit Care Med. 2020;201(11):1372-1379. doi:10.1164/ rccm.202003-0543OC

36. Felsenstein S, Herbert JA, McNamara PS, et al. COVID-19: immunology and treatment options. Clin Immunol. 2020;215:108448. doi:10.1016/j.clim.2020.108448

37. Wang L. C-reactive protein levels in the early stage of COVID-19. Med Mal Infect. 2020;50(4):332-334. doi:10.1016/j.medmal.2020.03.007

38. Bai L, Wang M, Tang XQ. Thinking about the hot issues in the diagnosis and treatment of novel coronavirus pneumonia. Hua Xi Med. 2020;35(02):125-131. doi:10.7507/1002-0179.202002044

39. Chen H, Ai L, Lu H, et al. Clinical and imaging features of COVID-19. Radiol Infect Dis. 2020;7(2):43-50. doi:10.1016/j. jrid.2020.04.003

40. Liu X, Wang J, Xu X, et al. Patterns of IgG and IgM antibody response in COVID-19 patients. Emerg Microbes Infect. 2020;9 (1):1269-1274. doi:10.1080/22221751.2020.1773324

41. To KK-W, Tsang OT-Y, Leung W-S, et al. Temporal profiles of viral load in posterior oropharyngeal saliva samples and serum antibody responses during infection by SARS-CoV-2: an observational cohort study. Lancet Infect Dis. 2020;20(5):565-574. doi:10.1016/s14733099(20)30196-1

42. Dai L, Gao GF. Viral targets for vaccines against COVID-19. Nat Rev Immunol. 2021;21(2):73-82. doi:10.1038/s41577-020-00480-0
International Journal of General Medicine

\section{Publish your work in this journal}

The International Journal of General Medicine is an international, peer-reviewed open-access journal that focuses on general and internal medicine, pathogenesis, epidemiology, diagnosis, monitoring and treatment protocols. The journal is characterized by the rapid reporting of reviews, original research and clinical studies across all disease areas. The manuscript management system is completely online and includes a very quick and fair peer-review system, which is all easy to use. Visit http://www.dovepress.com/ testimonials.php to read real quotes from published authors. 